\title{
Prevalence of COVID-19 infection in asymptomatic school children
}

\author{
Hümeyra Aslaner ${ }^{1 \oplus}$, Ali Ramazan Benlì ${ }^{2 \oplus}$, Erhan Şimşek ${ }^{3 \oplus}, Z_{\text {übeyde Korkmaz }}^{4 \odot}$ \\ ${ }^{1}$ Department of Family Medicine, Kayseri City Hospital, Kayseri; ${ }^{2}$ Department of Family Medicine, Karabük University Faculty of \\ Medicine, Karabük; ${ }^{3}$ Department of Family Medicine, Kayseri Felahiye Public Hospital, Kayseri; 'Department of Nursing, Nuh Naci \\ Yazgan University Faculty of Health Sciences, Kayseri, Turkey.
}

\begin{abstract}
Background. With the onset of the COVID-19 pandemic, discussions regarding the prevalence of COVID-19 in children and the association of this with education have started. This study aimed to determine the prevalence of COVID-19 infection in asymptomatic school children within a limited period while face-to-face education continued.
\end{abstract}

Methods. This is a descriptive and retrospective study. Screening was carried out in the schools in the three major districts of the metropolitan municipality when face-to-face education was practiced. COVID-19 RT-PCR swab samples were collected from 4,658 students from 46 schools at preschool, primary, secondary, and high school levels by using the stratified sampling method. Screening results were retrospectively analyzed by the researchers.

Results. The mean age of the children included in the study was 10.6 3.2 (5-17). Only 46 students' COVID-19 RT-PCR results were positive; the positivity rate was higher in male students than in female students $(\mathrm{p}>0.05)$; the students living in the third region had a higher positivity rate than the other students, there was a statistical difference between them $(\mathrm{p}<0.001)$; there were no positive cases in $26(56.7 \%)$ schools, and the spreader rate of the school children was $0.98 \%$.

Conclusions. We determined in the study that the prevalence of COVID-19 infection was not high in asymptomatic school children in the period when schools were open. This may play a role in directing the education and training during the pandemic.

Key words: COVID-19, prevalence, school children, education.

Coronavirus disease 2019 (COVID-19), caused by the severe acute respiratory syndrome coronavirus 2 (SARS-CoV-2), is an infectious respiratory disease that affects humans. The disease, first seen in China in the last month of 2019, rapidly spread worldwide and was declared a pandemic by the World Health Organization (WHO). Due to the pandemic, all countries around the world have taken various measures for the pandemic. These measures include a curfew, city lockdown,

\footnotetext{
Hümeyra Aslaner

drhumeyra@hotmail.com
}

Received 10th September 2021, 7th November 2021, accepted 28th December 2021. physical distancing, avoiding high-risk spaces like crowded indoor gatherings, staying home when ill, wearing face masks, and using contact tracing apps. ${ }^{1}$ One of the most important of these measures was to suspend education for a while. With the prolongation of the pandemic, some countries have started the education of preschools and school children with distance education, while some countries have continued face-to-face education by taking protective measures. ${ }^{2}$ With the onset of face-to-face education, discussions regarding the prevalence of COVID-19 in children have started.

What is known about the risks of COVID-19 for children changes the understanding of how it affects children as the information about 
COVID-19 increases. ${ }^{2,3}$ In the early stages of the pandemic, it was thought that children had mild and asymptomatic COVID-19 and that the risk of transmission was lower. ${ }^{4}$ However, it has been determined over time that children with COVID-19 may also require hospitalization and critical care. ${ }^{5,6}$ Cura et al. reported a high rate $(8.6 \%)$ in children assessed with the suspicion of COVID-19. ${ }^{5}$

On the contrary to these studies, there are also reports revealing that COVID-19 is rare among children. ${ }^{7-10}$ It has been reported that $2.1 \%$ of the cases infected with COVID-19 are children under the age of 18. According to the current information provided by the Chinese Centers for Disease Control and Prevention, 416 (0.9\%) out of 44,672 individuals were below the age of 10 and $549(1.2 \%)$ were between the ages of 10 and 18 by the 11th of February 2020. ${ }^{11}$

It is important to carry out school screenings to protect and improve public health during pandemics, and the family physicians, health professionals working in the community health centers, and school health nurses take an active role and identify children in the risk group before hand. ${ }^{2}$

This study aimed to determine the prevalence of COVID-19 infection in asymptomatic school children within a limited period while face-toface education continued.

\section{Material and Methods}

All the procedures performed in studies involving human participants followed the ethical standards of the institutional and/ or national research committee and the 1964 Helsinki declaration and its later amendments or comparable ethical standards. The institutional approval was obtained from the Provincial Health Directorate (93079172-703.01) and the Ministry of Health (2020-11-18T15_37_29), and ethical approval was obtained from Nuh Naci Yazgan University Ethics Committee (2020/27).
This was a descriptive and retrospective study. In this study, the results of COVID-19 RT-PCR tests performed at the schools by the Provincial Health Directorate for screening in asymptomatic children were obtained from the records and retrospectively assessed.

\section{Study Design and Setting}

The duration of compulsory education for children in Turkey is 12 years. Before compulsory education, children receive preschool education. The first four years of compulsory education are a primary school, the second four years are a secondary school, and the third four years are high school education.

Schools were closed on March 16, 2020, when the pandemic began in Turkey. Face-to-face education started on September 21, 2020. Some precautions were taken at schools as faceto-face education started. Wearing a mask became compulsory. Social distancing rules were carefully followed in the classrooms and in common areas such as dining halls and the seating arrangements were adjusted according to these rules. The school canteens were closed. The use of sports halls, swimming pools and school clubs was suspended. Mass ceremonies were canceled. The length and number of lessons were decreased and the length of break times was increased. The classrooms were ventilated by keeping the windows open during break times. Adults except for teachers and staff in charge were not allowed in the schools. The temperature of the students and teachers was taken before attending the classes. The teachers and students with symptoms were immediately referred for PCR test analysis. Forty-five days after face-to-face education started, the Provincial Health Directorate carried out screening at schools in 3 major districts to evaluate the prevalence of COVID-19 in asymptomatic school children during the faceto-face education period. Socio-demographic characteristics of these three districts are as follows; Melikgazi: The population is 555,671; the population density is 3295; the development 
index is 3.32; the literacy rate is $98.1 \%$; the number of students per classroom is 59 , and there are 1398 factories in the two organized industrial zones of Melikgazi. Kocasinan: The population is 391,661 ; the population density is 226; the development index is 3.32; the literacy rate is $97.1 \%$; the number of students per classroom is 34; and it is the district where the migration from abroad (Syria, Afghanistan, etc.) is the highest. Talas: The population is 157,695; the population density is 336 ; the development index is 0.59 ; the literacy rate is $98.1 \%$; the number of students per classroom is 36 , and it is the district where the number of universities is higher. Between November 9 and 15, 2020, the students in 46 schools were screened. The cases who were positive for COVID-19 RT-PCR test were accepted as cases infected with COVID-19. The students who did not have any symptoms and signs of COVID-19 disease and those who had no history of contact were included in the screening. Throat or nasal swab samples were used for the RT-PCR test. Consent to collect swab samples were obtained from all children who were planned to be included in the screening and their parents.

\section{Study Sample and Properties}

In this process, 48 schools were randomly determined among the districts, with four schools from each level by the Provincial Health Directorate. Schools were selected using the stratified sampling method. Two schools were not included in the screening as the school management did not give consent. A power analysis was performed using the $G^{*}$ Power 3.1.0 analysis program to determine the sample size in our study. The number of people participating in the study with a population size of 176,000 was determined as a minimum of 3700 ( $\alpha$-value: 0.05 , ß-value: 0.80$)$.

In our study, the data of 4,658 students between the ages of 5 and 18 who were studying in preschool (kindergarten), primary school, secondary school, and high school and screened by the Provincial Health Directorate were evaluated. The screening results were analyzed according to the demographic characteristics and school levels. The data were obtained from the Provincial Health Directorate records and the Public Health Management System.

\section{Real-Time Reverse Transcriptase Polymerase Chain Reaction}

Real-time reverse-transcription PCR was performed using Coronex-COVID-19 (Ver.2.0) Multiplex RT-qPCR Diagnosis Kit (DS Bio and Nano Technology, Ankara, Turkey). A $20-\mu \mathrm{L}$ of reaction mix contained $5 \mu \mathrm{L}$ of RNA, 12.5 $\mu \mathrm{L}$ of CORONEX-COVID-19 DS Mix E [RTqPCR master mix], and $2.5 \mu \mathrm{L}$ of CORONEXCOVID-19DS PP1 primer and probe mix [Orf1ab and $\mathrm{N}$ genes for SARS-CoV-2 detection, Rnase $P$ gene for internal control]. Positive control for amplification control and no-template control were used to assess contamination. Thermal cycling was performed at $48{ }^{\circ} \mathrm{C}$ for $20 \mathrm{~min}$ for reverse transcription, followed by $95{ }^{\circ} \mathrm{C}$ for 5 min, and then 35 cycles at $95^{\circ} \mathrm{C}$ for $5 \mathrm{~s}$ and $60^{\circ} \mathrm{C}$ for $10 \mathrm{~s}$ in Rotor-Gene Q device (Qiagen, Hilden, Germany). Cycle threshold $(\mathrm{Ct})$ values of less than 33 were defined as positive. According to the information from the user manual of CORONEX COVID-19 Multiplex qPCR Kit sensitivity: $97.06 \%$ [95\% CI : 94.92\% $-98.47 \%$ ] and specificity: 100\% [96.31\%-100\%].

\section{Statistical Analysis}

Data analysis of the study was performed using SPSS version 22.0 (IBM Corp., Armonk, NY, USA) software program. In the data analysis, frequency, mean, median, standard deviation, and minimum and maximum values were used as descriptive data. Chi-square test was used in the comparison of categorical data; Student's T-test was used in paired groups with normal distribution in numerical data, and Mann-Whitney $U$ test was used in groups that did not comply with a normal distribution. In comparing three or more groups that did not comply with the normal distribution, the Kruskal Wallis test was used, Post-hoc Dunn's correction was performed, and $\mathrm{p}<0.05$ was considered statistically significant. 


\section{Results}

The mean age of the students included in the study was $10.6 \pm 3.2(5-17)$ years. According to the results, $50.9 \%(n=2370)$ of the students included in the study were female, $34.8 \%$ of the students were in primary school, $43.3 \%$ were in the age group of $6-10$, and $49.7 \%$ were educated in the 1 st region. In the study, the number of positive RT-PCR students was 46 $(0.9 \%)$ (Table I). The median age of the students with positive RT-PCR test screening results was 11 , and there was no statistical difference between the positivity rate and age groups ( $p$ $=0.84$ ). Although the number of positive cases among the male students was higher than the female students, there was no statistical difference between them $(p=0.07)$. According to the results of the RT-PCR tests, the positivity rate of students living in the 3rd region was higher than the positivity rate of students living in the other regions, and the difference was statistically significant $(\mathrm{p}<0.001)$ (Table II).

While positivity was mostly observed in the children attending secondary schools in the 1st region, positive cases were higher in the

Table I. Socio-demographic characteristics of students.

\begin{tabular}{lcc}
\hline Characteristics & $\mathrm{n}$ & $\%$ \\
\hline Mean (SD) age, year & $10.6(3.2)$ & $5-17$ \\
Gender & & \\
Male & 2288 & 49.1 \\
Female & 2370 & 50.9 \\
Age Groups & & \\
5 years & 250 & 5.4 \\
6-10 years & 2106 & 45.2 \\
11-15 years & 1892 & 40.6 \\
16 years and above & 410 & 8.8 \\
Level of Development & & \\
1st Region (Melikgazi) & 2313 & 49.6 \\
2nd Region (Kocasinan) & 1009 & 21.7 \\
3rd Region (Talas) & 1336 & 28.7 \\
RT-PCR Result & & \\
Negative & 4612 & 99.1 \\
Positive & 46 & 0.9 \\
\hline
\end{tabular}

The Turkish Journal of Pediatrics • January-February 2022 children educated in primary schools in the 3rd region (Table III). A positive result was found in $20(43.5 \%)$ out of the 46 schools screened. In the study, positive results were found in 4,5 , and 6 students in 1 school of each region (Table IV).

\section{Discussion}

All age groups are sensitive to COVID-19. The disease progresses with different clinical features from mild to severe. ${ }^{12}$ The first COVID-19 case in children was reported from Shenzhen, China, on January 20, 2020. ${ }^{13}$ Later, many pediatric cases and case series started to be reported. ${ }^{5}$ In some studies, it has been reported that the rate of contracting COVID-19 is less in children than in adults, and the symptoms and signs are milder. ${ }^{14,15}$ According to the weekly report of morbidity and mortality by the CDC, among 149,082 U.S. COVID-19 cases who had been reported as of April 2, 2020, and whose ages were known, 2,572 (1.7\%) were patients under the age of 18 years and the rate was $2.4 \%$ in China. ${ }^{16,17}$ It was reported that $3 \%(n=202)$ of 6713 daily diagnosed COVID-19 cases in Turkey on 23.11.2020 were under the age of $15 .{ }^{18}$

Occasional or absent clinical findings in children may cause fewer tests and fewer diagnoses. It has been reported that the rate of infected children is low, and children constitute an important group in terms of spreading the virus. ${ }^{19}$ However, the data on this subject are insufficient and limited as children are evaluated within the scope of contact follow-up and reflect the children treated in hospitals. ${ }^{20}$ Our study is important because to the best of our knowledge there is no study on asymptomatic school children without a history of contact in the Turkish literature.

The epidemiological data and clinical observations reveal that the prevalence of COVID-19 is lower and the possibility of mild/ symptomatic COVID-19 is higher among young individuals, particularly among children. ${ }^{21}$ The Turkish National Pandemic Plan carries out filiation practices including the infected 
Table II. Evaluation of parameters according to the RT-PCR results of the students.

\begin{tabular}{lccc}
\hline \multirow{2}{*}{ Characteristics } & \multicolumn{2}{c}{ RT-PCR Result } & Test/ p-value \\
\cline { 2 - 3 } Age Groups (year) & Positive $\mathrm{n}(\%)$ & Negative $\mathrm{n}(\%)$ & \\
5 years & $3(6.5)$ & $247(5.4)$ & 0.837 \\
6-10 years & $19(41.3)$ & $2087(45.3)$ & 0.84 \\
11-15 years & $21(45.7)$ & $1871(40.6)$ & \\
16 years and above & $3(6.5)$ & $207(8.8)$ & \\
Gender & & 2.566 \\
Male & $28(60.9)$ & $2352(51)$ & \\
Female & $18(39.1)$ & & \\
Level of Development & & $2292(49.7)$ & 17.234 \\
1st Region (Melikgazi) & $21(45.7)$ & $1008(21.9)$ & 0.000 \\
2nd Region (Kocasinan) & $1(2.2)$ & $1312(28.4)$ & \\
3rd Region (Talas) & $24(52.2)$ & $4612(100)$ & \\
Total & $46(100)$ & & \\
\hline
\end{tabular}

Table III. Number of positive students by localization and level of schools.

\begin{tabular}{|c|c|c|c|}
\hline & Total Number of Students & Number of RT-PCR Positive Students & Positivity Rate /p \\
\hline \multicolumn{4}{|c|}{ 1St Region (Melikgazi) } \\
\hline Pre-school & 101 & 1 & 0.99 \\
\hline Primary school & 931 & 4 & 0.43 \\
\hline Secondary School & 1057 & 11 & 1.04 \\
\hline High school & 224 & 5 & 2.23 \\
\hline Total & $2313(49.66)$ & $21(45.66)$ & 0,90 \\
\hline p-value & 0.43 & 0.12 & 0.41 \\
\hline \multicolumn{4}{|c|}{ 2nd Region (Kocasinan) } \\
\hline Pre-school & 120 & 0 & \\
\hline Primary school & 552 & 0 & 0 \\
\hline Secondary School & 278 & 0 & 0 \\
\hline High school & 59 & 1 & 1.69 \\
\hline Total & 1009 (21.66) & $1(2.17)$ & 0.09 \\
\hline $\mathrm{p}$-value & 0.21 & 0.58 & 0.58 \\
\hline \multicolumn{4}{|l|}{ 3rd Region (Talas) } \\
\hline Pre-school & 29 & 1 & 3.45 \\
\hline Primary school & 623 & 11 & 1.77 \\
\hline Secondary School & 557 & 9 & 1.62 \\
\hline High school & 127 & 3 & 2.36 \\
\hline Total & $1336(28.68)$ & $24(52.17)$ & 1.7 \\
\hline p-value & 0.06 & 0.34 & 0.54 \\
\hline Overall total & $4658(100)$ & $46(0.98)$ & \\
\hline
\end{tabular}


Table IV. Number of schools according to positive RT-PCR test results of the students.

\begin{tabular}{lc}
\hline \multicolumn{2}{l}{ Number of positive students Number of schools (\%) } \\
\hline 0 & $26(56.5)$ \\
1 & $8(17.4)$ \\
2 & $5(10.8)$ \\
3 & $4(8.7)$ \\
4 & $1(2.2)$ \\
5 & $1(2.2)$ \\
6 & $1(2.2)$ \\
\hline
\end{tabular}

patients and contacts. Therefore, a higher rate of positivity can be detected in children with COVID-19 contact history or symptoms. ${ }^{5}$

At the time of this study, 19,273 RT-PCR tests were performed in the province and the test results of 3,785 people were positive. The rate of positive cases/tests in the province was $19.6 \%$ in the whole population. This rate was reported as $1.19 \%$ in children (under the age of 18 ) and $2.6 \%$ in school children (ages between 5 and 18). In our study, the positivity rate seen in asymptomatic school children was $0.98 \%$. According to the data of the Provincial Health Directorate, the rate of positive cases in the general population is lower in children compared with adults. In addition, the positivity rate of asymptomatic school children in our study was lower than the rate of positive cases among children between the ages of 5 and 18 detected in the province in the same period. The reason why the positivity rate in our study was lower than the rate in literature and school children in the province is probably that school children with a history of contact and symptoms were not included in the study and that the asymptomatic children were randomized in the study.

In studies on infected children in China and the USA, when the infection status of children was assessed according to gender, approximately $57 \%$ of them were boys. ${ }^{4}$ In our study, the rate of infection was higher in boys than in girls. It was reported in other studies that infected children were usually between the ages of 6 and $15 .{ }^{3,15}$ In our study, the positivity rate among children between the ages of 6 and 10 and 11 and 15 was higher, which is consistent with the findings in the literature. It may be due to the increase in the socialization of children as they get older and their careless behaviors in obeying social distancing rules. On the other hand, it may show that preschool children obey the determined rules more.

In countries with the idea that children would not comply with social distancing, masks, and hygiene rules, it was thought that children would first transmit COVID-19 to each other in educational institutions and then to their families; therefore, schools and daycare centers were closed. ${ }^{22}$ However, studies indicate no direct evidence on the impact of daycare and school closures on the COVID-19 outbreak. ${ }^{20,22}$ Contrary to these studies, there are also publications stating that closing schools is an effective method to prevent the spread of the pandemic. ${ }^{23-26}$ For this reason, it is stated that studies should aim to determine the rate of infection spreading of children in schools that have started face-to-face education. ${ }^{20,22}$ Our study was conducted in a period of transition to face-to-face education in Turkey. Schools' rate with no cases was $56.5 \%(n=26)$. The number of schools with no positivity was almost equal to the number of schools with positive cases. No clear view has been obtained from these results regarding the effect of the COVID-19 pandemic on preschool and school closures.

Today, epidemics and infectious diseases affect societies and people with poorer socioeconomic status. ${ }^{27}$ Economically disadvantaged people living in crowded houses where there is no social distancing, being employed in jobs that do not provide the opportunity to work from home, and similar factors increase the possibility of being exposed to COVID-19. ${ }^{28}$ The results of our study on localization support this. According to the RT-PCR test results, the positivity rate was higher in the students living in the 3rd region, where the level of development was the lowest $(\mathrm{p}<0.001)$. 
The most important limitation of our study was that the data of school-age children were withdrawn from the data processing system after RT-PCR screening, and the teachers and other school staff members were not included in the screening process. It is the first study performed on asymptomatic school children in Turkey, which is the strength of the study.

In conclusion, the COVID PCR positivity rate in asymptomatic school children was $0.98 \%$ in our study. Also, no positive cases were found in more than half of the schools. This study has revealed that the prevalence of COVID-19 infection in asymptomatic school children is not higher than the rates in symptomatic children and the general population. This may play a role in directing education and training during the pandemic as well as planning training about the pandemic and taking protective measures. However, the pediatric COVID-19 infectivity should not be ignored. Therefore, further studies are needed to confirm our observations.

\section{Author contribution}

The authors confirm contribution to the paper as follows: study conception and design: ARB, EŞ; data collection: ARB; analysis and interpretation of results: $\mathrm{HA}, \mathrm{ZK}$; draft manuscript preparation: HA, EŞ, ZK. All authors reviewed the results and approved the final version of the manuscript.

\section{Ethical approval}

The institutional approval was obtained from the Provincial Health Directorate (93079172703.01) and the Ministry of Health (202011-18T15_37_29), and ethical approval was obtained from Nuh Naci Yazgan University Ethics Committee (2020/27).

\section{Source of funding}

The authors declare the study received no funding.

\section{Conflict of interest}

The authors declare that there is no conflict of interest.

\section{REFERENCES}

1. Lang R, Benham JL, Atabati O, et al. Attitudes, behaviours and barriers to public health measures for COVID-19: a survey to inform public health messaging. BMC Public Health 2021; 21: 1-15. https://doi.org/10.1186/s12889-021-10790-0

2. Viner RM, Russell SJ, Croker H, et al. School closure and management practices during coronavirus outbreaks including COVID-19: a rapid systematic review. Lancet Child Adolesc Health 2020; 4: 397404. https://doi.org/10.1016/S2352-4642(20)30095-X

3. Dong $\mathrm{Y}, \mathrm{Mo} \mathrm{X}, \mathrm{Hu} \mathrm{Y}$, et al. Epidemiology of COVID-19 among children in China. Pediatrics 2020; 145: e20200702. https://doi.org/10.1542/peds.20200702

4. Tsankov BK, Allaire JM, Irvine MA, et al. Severe COVID-19 infection and pediatric comorbidities: a systematic review and meta-analysis. Int J Infect Dis 2021; 103: 246-256. https://doi.org/10.1016/j. ijid.2020.11.163

5. Cura Yayla BC, Ozsurekci Y, Aykac K, et al. Characteristics and management of children with COVID-19 in Turkey. Balkan Med J 2020: 341-347. https://doi.org/10.4274/balkanmedj. galenos.2020.2020.7.52

6. Parcha V, Booker KS, Kalra R, et al. A retrospective cohort study of 12,306 pediatric COVID-19 patients in the United States. Sci Rep 2021; 11: 1-10. https:// doi.org/10.1038/s41598-021-89553-1

7. Wang D, Hu B, Hu C, et al. Clinical characteristics of 138 hospitalized patients with 2019 novel coronavirus-infected pneumonia in Wuhan, China. JAMA 2020; 323: 1061-1069. https://doi.org/10.1001/ jama.2020.1585

8. Huang $\mathrm{C}$, Wang $\mathrm{Y}, \mathrm{Li} \mathrm{X}$, et al. Clinical features of patients infected with 2019 novel coronavirus in Wuhan, China. The Lancet 2020; 395: 497-506. https://doi.org/10.1016/S0140-6736(20)30183-5

9. Li Q, Guan X, Wu P, et al. Early transmission dynamics in Wuhan, China, of novel coronavirusinfected pneumonia. N Engl J Med 2020; 382: 11991207. https://doi.org/10.1056/NEJMoa2001316

10. Ko WC, Rolain JM, Lee NY, et al. Arguments in favour of remdesivir for treating SARS-CoV-2 infections. Int J Antimicrob Agents 2020; 55: 105933. https://doi.org/10.1016/j.ijantimicag.2020.105933 
11. The Novel Coronavirus Pneumonia Emergency Response Epidemiology Team. The epidemiological characteristics of an outbreak of 2019 novel coronavirus diseases (COVID-19) - China, 2020. China CDC Weekly 2020; 2: 113-122. https://doi. org/10.46234/ccdcw2020.032

12. Aslaner H, Aslaner HA, Gökçek MB, Benli AR, Yıldız $\mathrm{O}$. The effect of chronic diseases, age and gender on morbidity and mortality of COVID-19 infection. Iran J Public Health 2021; 50: 721-727. https://doi. org/10.18502/ijph.v50i4.5996

13. Chan JFW, Yuan S, Kok KH, et al. A familial cluster of pneumonia associated with the 2019 novel coronavirus indicating person-to-person transmission: a study of a family cluster. The Lancet 2020; 395: 514-523. https://doi.org/10.1016/S01406736(20)30154-9

14. Yayla BCC, Aykac K, Ozsurekci Y, Ceyhan M. Characteristics and management of children with COVID-19 in a tertiary care hospital in Turkey. Clin Pediatr (Phila) 2021; 60: 170-177. https://doi. org/10.1177/0009922820966306

15. Lu X, Zhang L, Du H; Chinese Pediatric Novel Coronavirus Study Team. SARS-CoV-2 infection in children. N Engl J Med 2020; 382: 1663-1665. https:// doi.org/10.1056/NEJMc2005073

16. CDC COVID-19 Response Team. Coronavirus disease 2019 in children - United States, February 12-April 2, 2020. MMWR Morb Mortal Wkly Rep 2020; 69: 422-426. https://doi.org/10.15585/mmwr. $\mathrm{mm} 6914 \mathrm{e} 4$

17. She J, Liu L, Liu W. COVID-19 epidemic: disease characteristics in children. J Med Virol 2020; 92: 747754. https://doi.org/10.1002/jmv.25807

18. T.C. Sağlık Bakanlığı. COVID-19 Günlük Durum Raporu, Türkiye. Sağlık Bakanlığı. Published online 2020: 1-5. https://covid19.saglik.gov.tr/ Eklenti/39507/0/covid-19-gunluk-durum-raporu23112020pdf.pdf (Accessed on November 27, 2020)

19. Cao Q, Chen YC, Chen CL, Chiu CH. SARS-CoV-2 infection in children: transmission dynamics and clinical characteristics. J Formos Med Assoc 2020; 119: 670-673. https://doi.org/10.1016/j.jfma.2020.02.009

20. Robert Koch Institute. Wiedereröffnung von Bildungseinrichtungen - Überlegungen, Entscheidungsgrundlagen und Voraussetzungen. Epidemiologisches Bulletin 2020; 19: 6-13. Available at: https://www.rki.de/DE/Content/Infekt/ EpidBull/Archiv/2020/Ausgaben/19_20.pdf? blob=publicationFile $\#$ page $=6$
21. Miri SM, Noorbakhsh F, Mohebbi SR, Ghaemi A. Higher prevalence of asymptomatic or mild COVID-19 in children, claims and clues. J Med Virol 2020; 92: 2257-2259. https://doi.org/10.1002/ jmv.26069

22. Simon A, Huebner J, Berner R, et al. Measures to maintain regular operations and prevent outbreaks of SARS-CoV-2 in childcare facilities or schools under pandemic conditions and co-circulation of other respiratory pathogens. GMS Hyg Infect Control 2020; 15: Doc22. https://doi.org/10.3205/ dgkh000357

23. Eubank S, Eckstrand I, Lewis B, Venkatramanan S, Marathe M, Barrett CL. Commentary on Ferguson, et al., "Impact of Non-pharmaceutical Interventions (NPIs) to Reduce COVID-19 Mortality and Healthcare Demand". Bull Math Biol 2020; 82: 52. https://doi.org/10.1007/s11538-020-00726-x

24. Kim S, Kim YJ, Peck KR, Jung E. School opening delay effect on transmission dynamics of Coronavirus disease 2019 in Korea: based on mathematical modeling and simulation study. J Korean Med Sci 2020; 35: 1-9. https://doi.org/10.3346/jkms.2020.35.e1

25. Koo JR, Cook AR, Park M, et al. Interventions to mitigate early spread of SARS-CoV-2 in Singapore: a modelling study. Lancet Infect Dis 2020; 20: 678-688. https://doi.org/10.1016/S1473-3099(20)30162-6

26. Prem K, Liu Y, Russell TW, et al. The effect of control strategies to reduce social mixing on outcomes of the COVID-19 epidemic in Wuhan, China: a modelling study. Lancet Public Heal 2020; 5: e261-e270. https:// doi.org/10.1016/S2468-2667(20)30073-6

27. Alpago H, Oduncu Alpago D. Socio-economic consequences of coronavirus. IBAD Journal of Social Sciences 2020: 8: 99-114. https://doi.org/10.21733/ ibad.716444

28. Patel JA, Nielsen FBH, Badiani AA, et al. Poverty, inequality and COVID-19: the forgotten vulnerable. Public Health 2020; 183: 110-111. https://doi. org/10.1016/j.puhe.2020.05.006 